\title{
Severity of Chronic Obstructive Pulmonary Disease as A predictor Of Outcome after Coronary Artery Bypass Grafting Surgery M.E.Sharaf ${ }^{1}$, M.A.El-Asal ${ }^{2}$, T.S.Esawy ${ }^{3}$ and B.M.Aglan ${ }^{4}$
}

${ }^{1}$ Critical care medicine Medicine, Dept., Nasser Institute for Research and Treatment, Cairo, Egypt.

${ }^{2}$ Internal medicine, Dept., Faculty of Medicine, Benha Univ., Benha, Egypt

${ }^{3}$ Pulmonology, Dept., Faculty of Medicine, Benha Univ., Benha, Egypt

${ }^{4}$ Cardiovascular surgery, Dept., Faculty of Medicine, Benha Univ., Benha, Egypt

E-mail:Mohamed12sharsf1988@gmail.com

\begin{abstract}
Context: COPD is an inflammatory illness of the airways, alveoli and microvasculature that shows persistent airflow limitation and small airways remodeling1. The pulmonary and systemic inflammation, changes in mucosal tissues, fibre and / or fibrous types, pulmonary vascular reshaping and angiogenesis are featured for the remodelling of the lungs1. Such pathological changes, in particular systemic inflammation and deregulated angiogenesis contribute to adverse effects in patients with COPD on different extrapulmonary organs. In clinical work, COPD is a common co-morbid disease in patients who are grafted by bypass of the coronary artery (CABG) with a 4-20.5percent incidence. COPD has traditionally been recognised as a contraindication of CABG2 operation. COPD was reportedly associated with increased postoperative mortality and morbidity such as prolonged mechanical ventilation, breathing failure, and atrial fibrillation in patients indicated for CABG. Studies have shown various COPD effects on postoperative morbidity and death3. Mortality rates between mild and moderate COPD patients and those without COPD have been reported to be comparable, but only serious COPD is associated with an increased mortality risk. In addition, some studies have demonstrated that the death rate of CABG patients was not influenced by airflow obstructions and COPD was not an independent risk factor for higher mortality and morbidity rates4. Objective: The aim of this study was to assess postoperative results of patients undergoing grafting surgery with chronic obstructive pulmonary disease. Methodology: This was a cross-sectional study of 100 patients undergoing surgery and was prepared for $\mathrm{CABG}$ over 3 years and data were collected from the cardiothoracic surgery registry data base system at the University of Benha. The primary endpoint was that the lung function test was subject to severe restrictive changes and that the FVC, FEV1 and PEF were significantly reduced and Respiratory complications remain the main cause of post-cardial surgical morbidity and can prolong hospital stays and increase costs so that pre- and postoperative pulmonary function assessment should be performed as a routine in CABG patients, even if the patients are asymptomatic and Pulmonary function assessment pre and post-operative should be done as a routine in CABG surgery patients even if the patients are asymptomatic and strongly recommend After coronary artery, lung rehabilitation bypasses grafting of all patients after CABG. Results: 100 patients undergone and prepped for CABG surgery were recruited for this study over a period of three years.) Table 1(shows the included patient demographic data $(n=100)$. After CABG, FEV1/FVC alterations in pulmonary function testing are both pre-operative and postoperative and are highly statistically significant $(\mathrm{p}=0.000)$. In addition, the next $40 \%$ experienced after respiratory problems with moderate postoperative pleural effusion, $22 \%$ had postoperative atelectasis, and $8 \%$ had postoperative pneumonia, which was statistically important. Conclusion: severe, reversible lung function restriction changes occurred in COPD patients in the early postoperative period, with many pulmonary complications in COPD patients following $\mathrm{CABG}$, and pre- and postoperative pulmonary functional evaluations should be carried out in routine patients undergoing $\mathrm{CABG}$ surgery, even if the patients are asymptomatic and CABG produces long-term changes.
\end{abstract}

Key words: CABG, COPD, Pulmonary function.

\section{Introduction}

Significant pulmonary disease was at one time considered an open heart surgery contraindication [5]. Currently, CABG has been performed more frequently in COPD patients because of the recent improvements in surgical techniques, anaesthesia and postoperative management. Therefore, the outcomes of the surgery in these vulnerable patients must be fully evaluated [6].

The treatment of heart disease ischemics should be guided regardless of COPD and vice versa.

COPD is an inflammatory illness of the airway, the alveoli and the microvasculature that has a chronic restriction of airflow and a remodelling of tiny airways.
The pulmonary and systemic inflammation, changes in mucosal tissue and/or fibrosis, lung vascular remodelling and angiogenesis are all featured in lung tissue remodelling. Such pathological changes, in particular systemic inflammation and deregulated angiogenesis contribute to adverse effects in patients with COPD on different extrapulmonary organs.

Different studies have shown COPD effects on postoperative morbidity and mortality. Mortality rates between mild and moderate COPD patients and those without COPD have been found to be similar, but only severe COPD is linked with an elevated mortality risk. In addition, some studies have shown that the mortality rate for CABG patients is not affected by airflow impairment, and COPD is not the 
independent risk factor for higher mortality and morbidity rates [2].

\section{Patients and Methods}

This is cross sectional study including 100 patients underwent \& prepared for $\mathrm{CABG}$ surgery over a period of 3 years and data were retrieved from the data base registry system of cardiothoracic surgery department at Benha University .

\subsection{Inclusion Criteria}

Previously diagnosed COPD patients, Active treatment, and follow-up in the pulmonary clinic for COPD, and the symptomatology of the COPD had to be dominant or codominant to the symptomatology of the ischemic heart disease according to the referring physician Risk stratification was performed according to Euro SCORE. Patients who require chronic (>3 months) bronchodilator therapy to avoid disability from obstructive airway disease, have a forced expiratory volume in 1 second (FEV1) less than $75 \%$ of the predicted value or less than $1.25 \mathrm{~L}$, or have room air partial pressure of oxygen less than $60 \mathrm{~mm}$ $\mathrm{Hg}$ or partial pressure of carbon dioxide greater than $50 \mathrm{~mm} \mathrm{Hg}$ will be considered COPD patients.

\subsection{Exclusion Criteria}

History of other comorbidities. Simultaneous valve surgery with $\mathrm{CABG}$ or significant surgical procedure other than median sternotomy.

\subsection{Ethical Considerations}

The collected data will be used for research purpose only, approval of the participants will be mandatory by getting a written consent after informing them about the study. Study protocol will be presented to and approved by the Ethics Committee of the Scientific Research -Faculty of Medicine - Benha University.

Study Procedures:

All patients enrolled in the study was subjected to the following :

\section{A. Complete history taking}

- Demographic data (Age, Gender, Occupation, Socioeconomic status, Residence and Special habits e.g., smoking) .

- Duration since COPD diagnosis and home medications.

- The history and symptoms of coronary artery disease .

- Family history of Cardiac and pulmonary diseases .

B. Detailed clinical examination

- General examination: Anthropometric measures (Weight, length and body mass index (BMI)).

- Vital signs (blood pressure, heart rate, respiratory rate and temperature).

- Assessment of oxygen saturation by pulse oximetry.

- Chest examination.

\section{Laboratory investigations \\ - CBC. \\ - Arterial blood gases. \\ - Serum Na and K level.}

D. Imaging

- Chest X-ray.

- Echocardiography.

- Pulmonary function tests (PFT)

\section{Outcomes}

- Mortality.

- Infection (deep and superficial sternal wound

infection and saphenous vein harvest wounds).

- Deep vein thrombosis.

- Pulmonary embolism.

- Prolonged mechanical ventilation postoperative.

- Readmission within 30 days postoperatively for the following diseases: acute myocardial infarction, pneumonia and acute respiratory failure

\subsection{Statistical Analysis}

Data were analyzed using Statistical Program for Social Science (SPSS) version 24. Quantitative data were expressed as mean \pm standard deviation (SD). Qualitative data were expressed as frequency and percentage.

We the following tests of significance: Independent-samples t-test, Chi-square (X2) test. Statistical significance was assessed at $\mathrm{P}$ values less than 0.05 .

\subsection{Statistical Analysis}

Data were analyzed using Statistical Program for Social Science (SPSS) version 24. Quantitative data were expressed as mean \pm standard deviation (SD). Qualitative data were expressed as frequency and percentage. We the following tests of significance: Independent-samples t-test, Chi-square (X2) test.

\section{Results}

The study enrolled 100 acute myocardial infarction (STEMI) patients who underwent primary coronary intervention.

Patients were divided into two groups:

- Group I: (Study) 50 patients.

- Group II: (Control) 50 patients.

Table (1) describes the demographic data of our study population. The age ranged from 35 to 75 years, the mean age was $57.14 \pm 6.38$, the mean weight was $72.56 \pm 9.86$, the mean preoperative of height was $165.88 \pm 5.69$, the mean preoperative of the BMI was $22.75 \pm 3.12$, the mean preoperative of the percent of smokers was 98 , the mean preoperative of the percent of the hypertensive patient was 72 , the mean preoperative of the percent of the Diabetic patient was 40. Before the operation $\mathrm{x}$ ray was done to the patient as shown in table (2) it shows that $5 \%$ of the patient had normal $x$ ray, $2 \%$ of the patient had hyperinflated chest, $1 \%$ of the patient have mild effusion, $6 \%$ of the 
patient had Emphysematous bullae, 3\% of the patient had cardiomegaly and $13 \%$ of the patient had Prominent vascular marking.

After the operation $\mathrm{X}$ ray was done to the patient as shown in table (3) It shows that $14 \%$ of the patient have normal $\mathrm{x}$ ray, $11 \%$ of the patient have hyperinflated chest, $40 \%$ of the patient have pleural effusion, $5 \%$ of the patient have pneumonia, $5 \%$ of the patient have cardiomegaly, $22 \%$ of the patient had atelectasis.

PFT was done to COPD patient 1 day before the operation and at 7 th post-operative day Data are presented as Mean \pm SD .and shows that Forced vital capacity(FVC) was $91.190 \pm 15.658$,decreased postoperative up to $60.110 \pm 12.039$ as shown in table (9) and it is statistically significant ,Forced Expiratory Volume in the 1st second (FEV1) was 65.300+8.128 preoperative and decreased to $58.310 \pm 10.095$ postoperative as shown in table (7) and it is statistically significant, ratio of Forced Expiratory Volume in the 1st second (FEV1) / Forced vital capacity(FVC) (FEV1/FVC) preoperative was $68.490 \pm 7.355$ post-operative was $106.640 \pm 16.734$ as shown in table (10) and it is statistically significant, Peek expiratory flow rate (PEF)preoperative was $45.21 \pm 11.0125$, while postoperative was $35.912 \pm 9.417$ as shown in table (9) and it is statistically significant ,Peek expiratory flow rate $25-75$ was 56.350 \pm 15.566 preoperative, postoperative was $55.970 \pm 556$ as shown in in table(11).

Table (1) Demographic Data of the study population.

\begin{tabular}{lc}
\hline Variables & Mean \pm SD \\
\hline Age (years) & $57.14 \pm 6.38$ \\
Weight (kgs) & $72.56 \pm 9.86$ \\
Height $(\mathbf{c m})$ & $165.88 \pm 5.69$ \\
BMI $($ Kg/m2) & $22.75 \pm 3.12$ \\
Smoker (n) & 98 \\
Hypertension (n) & 72 \\
Diabetes Mellitus (n) & 40 \\
\hline
\end{tabular}

Table (2) shows preoperative distribution of radiographic signs.

\begin{tabular}{lcc}
\hline & X Ray Pre & \\
& $\mathbf{N}$ & $\%$ \\
\hline Normal & 56 & 56 \\
mild effusion & 1 & 1 \\
prominent vascular marking & 13 & 13 \\
Hyperinflated chest & 21 & 21 \\
Cardiomegaly & 3 & 3 \\
emphysematous bullae & 6 & 6 \\
Total & 100 & 100 \\
\hline
\end{tabular}

Table (3) shows postoperative distribution of radiographic signs.

\begin{tabular}{lll}
\hline & X Ray Post & \\
& $\mathbf{N}$ & $\%$ \\
\hline Normal & 14 & 14 \\
Hyperinflated chest & 11 & 11 \\
Cardiomegaly & 5 & 5 \\
Atelectasis & 22 & 22 \\
Pneumonia & 8 & 8 \\
pleural effusion & 40 & 40 \\
Total & 100 & 100 \\
\hline
\end{tabular}


Table (4) shows perioperative radiographic changes. There is a statistically significant changes ( $p$ value $=0.036)$, this table shows that there is significant change in the radiographic signs postoperative.

\begin{tabular}{|c|c|c|c|c|c|c|c|c|}
\hline \multirow{2}{*}{ X Ray Pre } & \multicolumn{8}{|c|}{ X Ray Post } \\
\hline & normal & $\begin{array}{r}\text { Hyper } \\
\mathrm{cl}\end{array}$ & $\begin{array}{l}\text { flated } \\
\text { st }\end{array}$ & cardiomegaly & Atelectasis & pneumonia & $\begin{array}{l}\text { pleural } \\
\text { effusion }\end{array}$ & total \\
\hline \multirow{2}{*}{ normal } & $\mathrm{N}$ & 10 & 8 & 3 & 9 & 4 & 22 & 56 \\
\hline & $\%$ & 10.00 & 8.00 & 3.00 & 9.00 & 4.00 & 22.00 & 56.00 \\
\hline \multirow{2}{*}{ mild effusion } & $\mathrm{N}$ & 0 & 0 & 0 & 0 & 1 & 0 & 1 \\
\hline & $\%$ & 0.00 & 0.00 & 0.00 & 0.00 & 1.00 & 0.00 & 1.00 \\
\hline \multirow{2}{*}{$\begin{array}{c}\text { prominent } \\
\text { vascular } \\
\text { marking }\end{array}$} & $\mathrm{N}$ & 0 & 2 & 0 & 2 & 1 & 8 & 13 \\
\hline & $\%$ & 0.00 & 2.00 & 0.00 & 2.00 & 1.00 & 8.00 & 13.00 \\
\hline \multirow{2}{*}{$\begin{array}{c}\text { Hyperinflated } \\
\text { chest }\end{array}$} & $\mathrm{N}$ & 1 & 0 & 2 & 9 & 1 & 8 & 21 \\
\hline & $\%$ & 1.00 & 0.00 & 2.00 & 9.00 & 1.00 & 8.00 & 21.00 \\
\hline \multirow{2}{*}{ cardiomegaly } & $\mathrm{N}$ & 1 & 0 & 0 & 0 & 0 & 2 & 3 \\
\hline & $\%$ & 1.00 & 0.00 & 0.00 & 0.00 & 0.00 & 2.00 & 3.00 \\
\hline \multirow{2}{*}{$\begin{array}{c}\text { Emphysematous } \\
\text { bullae }\end{array}$} & $\mathrm{N}$ & 2 & 1 & 0 & 2 & 1 & 0 & 6 \\
\hline & $\%$ & 2.00 & 1.00 & 0.00 & 2.00 & 1.00 & 0.00 & 6.00 \\
\hline \multirow{2}{*}{ Total } & $\mathrm{N}$ & 14 & 11 & 5 & 22 & 8 & 40 & 100 \\
\hline & $\%$ & 14.00 & 11.00 & 5.00 & 22.00 & 8.00 & 40.00 & 100.00 \\
\hline \multirow[t]{2}{*}{ Paired $t$} & X2 & & & & 35.703 & & & \\
\hline & P-value & & & & 0.036 & & & \\
\hline
\end{tabular}

Table (5) shows that the mean changes in pre and post-operative liver and kidney function.

\begin{tabular}{lcccc}
\hline & Pre & Post & t & P-value \\
\hline SGOT & $24.19 \pm 9.07$ & $32.16 \pm 11.73$ & -6.32 & 0.000 \\
SGPT & $22.30 \pm 11.01$ & $33.11 \pm 12.76$ & -7.95 & 0.000 \\
creatinine & $1.15 \pm 1.00$ & $1.23 \pm 0.38$ & 0.74 & 0.46 \\
\hline
\end{tabular}

Table (6) The Pre and Post-operative changes in arterial blood gases

\begin{tabular}{lcccc}
\hline & Pre & Post & t & p-value \\
\hline PH & $7.32 \pm 0.05$ & $7.41 \pm 0.04$ & 0.995 & 0.322 \\
Po2 & $86.85 \pm 7.41$ & $90.31 \pm 5.52$ & -3.73 & 0.000 \\
Pco2 & $39.87 \pm 2.51$ & $33.37 \pm 8.55$ & 7.209 & 0.000 \\
Hco3 & $26.99 \pm 4.14$ & $26.72 \pm 3.98$ & 0.446 & 0.657 \\
\hline
\end{tabular}

Table (7) shows perioperative changes of Forced Expiratory volume in the 1ST second (FEV1) of Pulmonary Function Test.

\begin{tabular}{lrrrrrr}
\hline & \multicolumn{2}{c}{ FEV1 } & \multicolumn{2}{c}{ Difference } & \multicolumn{2}{c}{ Paired t-test } \\
& Range & Mean \pm SD & Mean & SD & t & P-value \\
\hline Pre & $41-86$ & $65.30 \pm 8.12$ & & & & \\
Post & $24-86$ & $58.31 \pm 10.09$ & 6.99 & 11.32 & 6.17 & 0.000 \\
\hline
\end{tabular}

Table (8) shows perioperative changes of Peek Expiratory Flow Rate (PEF) of pulmonary function test.

\begin{tabular}{lcccccc}
\hline & \multicolumn{2}{c}{ PEF } & \multicolumn{2}{c}{ Difference } & \multicolumn{2}{c}{ Paired t-test } \\
& Range & Mean \pm SD & Mean & SD & t & P-value \\
\hline Pre & $22-77$ & $45.21 \pm 11.01$ & & & & \\
Post & $17-72$ & $35.91 \pm 9.41$ & -0.38 & 17.20 & -0.22 & 0.000 \\
\hline
\end{tabular}

Table (9) shows perioperative changes of Forced Vital Capacity (FVC) of Pulmonary Function Test (PFT).

\begin{tabular}{lcrrrrr}
\hline & \multicolumn{2}{c}{ FVC } & \multicolumn{2}{c}{ Difference } & \multicolumn{2}{c}{ Paired t-test } \\
& Range & Mean \pm SD & Mean & SD & t & P-value \\
\hline Pre & $51-125$ & $91.19 \pm 15.65$ & & & & \\
Post & $20-95$ & $60.11 \pm 12.03$ & 31.08 & 17.13 & 18.13 & 0.000 \\
\hline
\end{tabular}


Table (10) shows perioperative changes of the ratio between Forced Expiratory volumes in the 1st second (FEV1) and forced vital capacity (FVC) of Pulmonary Function Test.

\begin{tabular}{llllllc}
\hline & FEV1/ FVC & & Difference & & \multicolumn{2}{c}{ Paired t-test } \\
& Range & Mean \pm SD & Mean & SD & t & P-value \\
\hline Pre & $55-125$ & $68.49 \pm 7.35$ & & & & \\
Post & $48-166$ & $106.64 \pm 16.73$ & -38.15 & 19.74 & -19.32 & 0.000 \\
\hline
\end{tabular}

Table (11) shows perioperative changes of Peek Expiratory Flow Rate (FPF25-57) of Pulmonary Function Test (PFT).

\begin{tabular}{lllllll}
\hline & FPF25-57 & & Difference & \multicolumn{3}{c}{ Paired t-test } \\
& Range & Mean \pm SD & Mean & SD & t & P-value \\
\hline \multirow{2}{*}{ Pre } & $26-107$ & $56.35 \pm 15.56$ & & & & 0.22 \\
\hline
\end{tabular}

\section{Discussion}

In this research we assessed COPD patients' pulmonary functions before and after CABG surgery, since PFTS had been pre-operatively and early after surgery. Previous studies only showed some preoperative PFTs or were conducted at a single point after surgery.

The aim of this research was to evaluate and identify variables that may affect such changes in FVC, FEV1/FVC, FEV1 after CABG.

The present study has also shown that the postoperative period of coronary artery grafting is causing damage to the pulmonary function, and pulmonary complications are among the most frequent complications reported following coronary artery bypass grafting (CABG).

It was apparent from the preoperative evaluation that our patients did not have a restricted parenchymal lung condition. There was a widespread reduction in the PFT variable in the postoperative phase up to one month following the CABG. All parameters except FEV1/FVC indicated a reduction. This shows a restrictive pattern or respiratory ventilation defect. Restrictive patterns could be due to changes in Chest Wall mechanics that affect their performance secondary to changes in the Chest Wall as shown below. The integrity of the chest wall, such as sternotomy injury to the chest wall, diaphragmatic paresis due to pericardio refrigeration, affects a number of factors [7].

Rib fracture, costochondral-cartilage retraction, undetected atelectasis, sternal restriction of blood supply to intercostal muscles, violation of pleural space impairs the integrity of the chest wall [8].

We compared our Table $(7,8,9,10 \& 11)$ results with other studies and found the same results as shown below:

Katiyar et al performed a study in 71 individuals with heart surgery on-pump. Pulmonary function was evaluated prior to and after surgery on the 3rd, 5th and 7 th days of surgery. Data including surgical details, risk factors information and pulmonary function assessment were obtained. In postoperative days 3, 5 and 7, the FEV1 and forced vital capacity were substantially reduced compared to preoperative values. FEV1 declines were $41 \%, 29 \%$, and $16 \%$, while forced vital capacity was $42 \%, 29 \%$, and $19 \%$ sequentially on postoperative days 3,5 , and 7. Multivariate analysis was carried out to identify postoperative FEV1 variables and compulsory vital capacities [9].

The pulmonary function of Westerdahl et al examined 4 days and 4 months after the CABG surgery and showed the significant decrease in lung function after the operation. Patients exhibited a substantial reduction (6-13 percent) of preoperative values in vital capacity ( $P$ $<0.001) 4$ months after surgery. Inspiratory capacity ( $\mathrm{P}$ $<0,001)$, forced volume in $1 \mathrm{~s}(\mathrm{P}, 0,001)$, peak expiratory flow rate $(\mathrm{P}<0,001)$, residual capability functional $(\mathrm{P}=0,05)$, total pulmonaire capability $(\mathrm{P}<$ $0,001)$ and single carbon diagnostic capacity $(\mathrm{P}<0,01)$ 10 . Gade et al. performed a research to assess sequential changes in the pulmonary function testing for 4 months after surgery. The research comprised 50 patients having CABG operations and their pulmonary functions were evaluated 7 days, 1 month and 4 months after the procedure and again. It has been observed that on 7 th postoperative day, the forced vital capacity (FVC) fell from $85 \%$ of its anticipated preoperative value to $56 \%$ $(\mathrm{P}=0.0000)$, recovered 1 month after and 84.2 percent $(\mathrm{P}=0.4008) 4$ month after surgery to 71.6 percent $(\mathrm{P}=$ $0.0000)$. Forced expiratory volume dropped in 1 st second (FEV1) from 88.38 percent to 59.06 percent $(\mathrm{P}=0.0000)$ on the 7 th postoperative date and recovered to 75.42 percent $(\mathrm{P}=0.000) 1$ month after operation and 4 months after surgery to 85.78 percent $(\mathrm{P}=0.0308)$. The ratio of FEV1/FVC slightly increased from $79 \%$ to $81 \%$ on the 7th day of postoperativity and 1 month after and after, reaching 78\%, 4 months after the operation that suggested a restrictive ventilatory defect [11].

Jenkins et al. found the decrease of a mean FVC in 77 patients getting IMA grafts to 36 percent on the second postoperative day and in 33 patients receiving SVGs to 45 percent in the pre-operative value.

Pulmonary function before and 1 week after coronary artery bypass grafting was investigated by Van Belle et al. They found that the FVC dropped to $33 \%$ of the preoperative value, which is remarkably comparable to 
the reduction in our study, for seven days after operation.

At Open heart surgery Vaidya et al. reported longterm breathing outcome and found that, despite hemodynamic and functional recovery, spirometry remained compromised in all 31 patients after 3 months. The cardiopulmonary bypass treatment also affects pulmonary function [12].

Berrizbeitia et al. reported the postoperative pulmonary mechanics impact of sternotomy and alleviated the severe restrictive pattern of respiratory characteristics after CABG [13].

Fuster et al. have documented the impact of obstructive lung disease on lung function following CABG14 and have shown significant limiting patterns of pulmonary function after CABG [14].

Lizak et al. identified FEV1 <LLN as the strongest forecast predictor for post-CABG problems regardless of concurrent COPD. FEV1 <LLN patients had superior results following OPCAB compared with post-CABG 15 patients.

Table (1) provides demographic information on cases, median age: 57 years of age, weight: 72 , height: 165, BMI: 22, 98 smokers.

Table (5) presents liver function tests before surgery and indicates that the typical patient liver function is high in most patients, but has increased liver function after surgery. It was also shown that $95 \%$ of the patient had a normal kidney function test, and the mean creatinine level was $1.15 \%$, after a $40 \%$ to $1.23 \%$ operating renal function test.

This has been in accordance with the research by zakeri et al on 385 patients undergoing CABG surgery and postoperative liver function tests and Statistical analyses showed direct and substantial links between changes in LFT and pumping time, aortic crossclamping time and usage of IABP [16].

Arterial blood gases before or after operation were shown by Table 6 , showing that $\mathrm{PH}$ had risen from 7.32 preoperative to 7.41 postoperative, $\mathrm{PO} 2$ had a mean of 86 preoperative and 90 postoperative and that the mean of pco2 preoperative had been 39 after 33, HCO3 had a near mean pre-operative or postoperative value 26 , most patients had post-operative respiratory alkalosis.

In agreement with safari et al, who investigated the relationship between pump life and blood gases in patients with on-pump $\mathrm{CABG}$, it was found that $\mathrm{PCO} 2$ had relatively decreased within the long pump time group six hours and three days after open heart ICU admission and patients had a degree of respiratory alkalosis $(\mathrm{P}=0.04)$ [17].

Before surgery $\mathrm{x}$ ray was performed, the patient had normal $x$ ray as shown in Table 2; $5 \%$ of the patient had normal $x$ ray, $2 \%$ had chest hyperinfection, $1 \%$ was of moderate effusion, $6 \%$ of the patient had emphysema bullae, $3 \%$ had cardiomegaly and $13 \%$ had prominent vascular marking.

After the x-ray procedure, as shown in Table 3, it reveals 14 percent of the patient have normal x-rays, 11 percent have a hyperinflated chest, 40 percent a plural effusion, and 5 percent are relatively small in significant lung problems. Early postoperative mobilisation and excellent pain management.

Many individuals develop pleural effusions right after heart surgery. The observed incidence following CABG was 40 to 50 percent when chest radiographs were utilised to detect effusions. Most effusions were leftsided, minor, asymptomatic (limited to the costophrenic angle), and spontaneous.

These effusions have many causes, including postoperative bleeding, atelectasis, pneumonia, cardiogenic, and noncardiogenic pulmonary edam, pleurotomy in mammalian inner artery grafts, heart hypothermia damage, pleural lymph drainage disruption through internal mammary artery harvest and fluid leaks. Very infrequently have chylothorax produced pleural effusions, Effusions 2-3 weeks after surgery may be included in the post-pericardiotomy syndrome that occurs in $10 \%-40 \%$ of individuals following heart surgery. These outbreaks usually disappear after few months following surgery and do not need therapy 18 . Patients have pneumonia, cardiomegaly is 5 percent, atelectasis is 22 percent.

The reported pneumonia incidence following CABG varies from $2 \%$ to $22 \%$. Cigarette smoking is a significant pneumonia risk factor.

Long post-operative intubation and mechanical ventilation may lead to fan-associated pneumonia (VAP), whereas reintubation can lead to reoperative, respiratory, and cardiaque insufficiency. In patients with respiratory failure, VAP has an incidence of $9 \%$ to $21 \%$.

Factors that affect pulmonary mechanics after CABG:

1. Division of the sternum impair chest wall stability and decrease chest wall compliance and also duo to assumption that harvesting of the Internal mammary Artery (IMA) is likely to interfere with the blood supply of the sternum as the arterial supply of the sternum is derived from the periosteal plexuses fed by the branches of the IMA may led to decrease blood supply to the intercostal muscle may decrease the force of respiration with corresponding decrease in the pulmonary mechanics [19].

2. Increase the degree of diaphragmatic dysfunction. Currently, one of the most accepted explanations to justify the reduction in the pulmonary function after thoracic surgery is diaphragmatic dysfunction. This dysfunction starts in the manipulation of the viscera during the surgical procedure, causing reflex inhibition of the phrenic nerve and diaphragmatic paresis some studies have shown that the cardioplegic solution may cause thermal injury to the phrenic nerve. The cold can result in functional and structural abnormalities, damaging the conduction velocity, increasing the degree of diaphragmatic paresis, which may contribute with a greater drop in the pulmonary volumes and capacities [20].

3. Changes in the gas exchange and pulmonary mechanics increase the respiratory effort, favoring an accumulation of secretion, with a higher possibility of 
obstruction to the airflow, which may predispose the patient to atelectasis and pneumonia [21].

4. During CPB it is common to interrupt the pulmonary ventilation, as there is insufficient alveolar insufflation to active the production of surfactant by type II pneumocytes, thereby increasing the surface tension, which can cause alveolar collapse [22].

5. Arterial hypoxemia normally occurs after CABG and persists for some weeks, the mechanism of hypoxemia can be attributed to several tors, such as a change in the ventilation/perfusion ratio, hypoventilation, reduction in the diffusion capacity and shunts with the latter being the best documented in the immediate postoperative period after Cardiopulmonary bypass may led to related to a reduction in the pulmonary complacency and pulmonary function [23].

6. The contact of the blood with the oxygenator triggers a cascade effect of enzymatic changes, with the release of inflammatory cytokines, increases in the permeability of the alveolar-capillary membrane, reducing blood-gas membrane, which harms the pulmonary complacency and consequently, the pulmonary volume and e gas exchange. These factors might explain the highest drop in the oxygenation and led to a greater decrease in the FVC[24].

FEV1 below LLN predicted a higher incidence of reoperation, readmission to intensive care unit (ICU), sternal wound infection, pulmonary complications, and pulmonary edema after surgery[25].

\section{Conclusion}

1. Following $\mathrm{CABG}$ there is an early postoperative severe, reversible restrictive alteration in lung function in COPD patients.

2. In COPD patients following $\mathrm{CABG}$, several pulmonary problems occurred.

3. Pulmonary function assessment pre- and postoperative should be performed as a routine in CABG surgery patients, even if the patients are asymptomatic.

4. CABG causes long-term pulmonary function alterations such that a long-term lung rehabilitation programme is required.

\section{Limitations}

1. We suggest longer sample size research to solidify our results.

2. Pulmonary function pre- and postoperative assessment should be performed as a standard in patients who have CABG surgery even if the patients are asymptomatic.

3. We highly advise Following coronary artery, lung rehabilitation bypasses grafting of all patients after CABG.

Conflict of interest: none declared.

\section{References}

[1] KJ.Peerzada, Chronic Obstructive Pulmonary Disease: An Update on Therapeutics and Pathophysiological Understanding. Chronic
Lung Diseases. Springer.vol.5,pp.157-180, 2020.

[2] H. Zhao, L. Li, G. Yang, Postoperative outcomes of patients with chronic obstructive pulmonary disease undergoing coronary artery bypass grafting surgery: a meta-analysis. Medicine.vol.98(6),pp.550-560, 2019.

[3] A.Pooria, A.Pourya, A.Gheini, Postoperative complications associated with coronary artery bypass graft surgery and their therapeutic interventions.

Future Cardiology.vol.16(5),pp.481-496, 2020.

[4] AD. Morgan, R .Zakeri, JK. Quint, Defining the relationship between COPD and CVD: what are the implications for clinical practice? Therapeutic advances in respiratory disease.vol.4,pp.12-17,2018.

[5] LE. Samuels, MS .Kaufman, RJ. Morris, R. Promisloff, SK .Brockman, Coronary artery bypass grafting in patients with COPD. Chest.vol.113(4),pp.878-882,1998.

[6] G. Campo, R .Pavasini, M. Malagu, Chronic obstructive pulmonary disease and ischemic heart disease comorbidity: overview of mechanisms and clinical management. Cardiovascular drugs and therapy.vol.29(2),pp.147-157, 2015.

[7] J. Lerman, CJ. Coté, DJ. Steward, Cardiovascular Surgery and Cardiologic Procedures. Manual of Pediatric Anesthesia. Springer.vol.44,pp.389-450,2016.

[8] K.MacPhedran, E.Hillegass, Cardiovascular and thoracic interventions. Essentials of Cardiopulmonary Physical Therapy-EBook.vol.8,pp.375:364,2016.

[9] N. Katiyar, S. Negi, SL. Negi, GD. Puri, SKS.Thingnam , Assessment of factors affecting short-term pulmonary functions following cardiac surgery: A prospective observational study. Asian Cardiovascular and Thoracic Annals.

[10]E. Westerdahl, B. Lindmark, I .Bryngelsson, A. Tenling, Pulmonary function 4 months after coronary artery bypass graft surgery. Respiratory medicine.vol.97(4),pp.317322,2003

[11]SA. Gade, MM .Sagdeo, PK. Deshpande, AV.Sahasrabuddhe, Sequential Changes In Pulmonary Functions After Coronary Artery Bypass Graft Surgery. JK Science.vol.13(1),pp.11, 2011.

[12] VR .Vaidya, M. Lyle, WR. Miranda, LongTerm Survival of Patients With Left Ventricular Noncompaction. Journal of the American Heart Association.vol.10(2),pp.550590,2021.

[13]LD. Berrizbeitia, S. Tessler, IJ. Jacobowitz, P. Kaplan, JN.Cunningham, Effect of sternotomy and coronary bypass surgery on postoperative pulmonary mechanics: comparison of internal 
mammary and saphenous vein bypass grafts.Chest.vol.96(4),pp.873-876,1989.

[14]RG. Fuster, JAM. Argudo, OG. Albarova, Prognostic value of chronic obstructive pulmonary disease in coronary artery bypass grafting. European journal of cardio-thoracic surgery.vol.29(2),pp.202-209,2006.

[15] MK.Lizak, E. Nash, M .Zakliczynski, J. Sliwka, P. Knapik, M.Zembala, Additional spirometry criteria predict postoperative complications after coronary artery bypass grafting (CABG) independently of concomitant chronic obstructive pulmonary disease: when is off-pump CABG more beneficial? Polskie Archiwum Medycyny Wewnetrznej. Sep.vol.119(9),pp.550-7,2009.

[16] S. Zakeri, H. Vafaey, N. Banihashem, A. Alijanpour, H. Gholinia, C. Behzad, Evaluation of Liver Function Tests after Coronary artery bypass surgery (CABG). Caspian Journal of Internal Medicine.vol.12(1),pp.45,2021.

[17] A. Safari, A. Rostami, A. Kamali, Evaluation of the relationship between pump duration and arterial blood gases in patients undergoing onpump CABG. Journal of Cardiovascular Disease Research.vol.12(1),pp.27-31,2021.

[18]R. Tanveer, A.Khan, FREQUENCY OF PLEURAL EFFUSION IN CABG SURGERY PATIENTS IN WHOM THE INTERNAL THORACIC ARTERY WAS HARVESTED WITH INTACT PLEURA OR WITH PLEUROTOMY. Pakistan Heart Journal.vol.52(4),2019.

[19] T. Kazui, SD. Lick, C-H. Hsu, DA.Bull, ShortTerm Risk of Bilateral Internal Mammary Artery Grafting in Diabetic Patients. Elsevier, 2020.

[20] A. Bruni, E. Garofalo, L. Pasin, Diaphragmatic dysfunction after elective cardiac surgery: A prospective observational study. Journal of Cardiothoracic and Vascular Anesthesia.vol.34(12),pp.3336-3344,2020.

[21] W.Smith, A.Finley, J.Ramsay, Postoperative respiratory failure and treatment. Principles and Practice of Anesthesia for Thoracic Surgery. Springer.vol.5,pp.895-923,2019.

[22] Y-C. Wang, C-H. Huang, Y-K. Tu, Effects of positive airway pressure and mechanical ventilation of the lungs during cardiopulmonary bypass on pulmonary adverse events after cardiac surgery: A systematic review and meta-analysis. Journal of cardiothoracic and vascular anesthesia.vol.32(2),pp.748-759,2018.

[23]F. Yousefshahi, E. Samadi, O. Paknejad, Prevalence and Risk Factors of Hypoxemia after Coronary Artery Bypass Grafting: The Time to Change Our Conceptions. J Tehran Heart Cent.vol.14(2),pp.74-80,2019.
[24] A. Neumann, L. Serna-Higuita, H. Detzel, Offpump coronary artery bypass grafting for patients with severely reduced ventricular function-A justified strategy? Journal of Cardiac Surgery,2021.

[25]H. Zhao, L. Li, G. Yang, Postoperative outcomes of patients with chronic obstructive pulmonary disease undergoing coronary artery bypass grafting surgery: A meta-analysis. Medicine.vol.98,pp.45-60. ,2019. 